\title{
The association between intimate partner violence, alcohol and depression in family practice
}

\author{
Gail Gilchrist ${ }^{1,2}$, Kelsey Hegarty², Patty Chondros ${ }^{2}$, Helen Herrman³ ${ }^{3}$ Jane Gunn²
}

\begin{abstract}
Background: Depressive symptoms, intimate partner violence and hazardous drinking are common among patients attending general practice. Despite the high prevalence of these three problems; the relationship between them remains relatively unexplored.

Methods: This paper explores the association between depressive symptoms, ever being afraid of a partner and hazardous drinking using cross-sectional screening data from 7667 randomly selected patients from a large primary care cohort study of 30 metropolitan and rural general practices in Victoria, Australia. The screening postal survey included the Center for Epidemiological Studies Depression Scale, the Fast Alcohol Screening Test and a screening question from the Composite Abuse Scale on ever being afraid of any intimate partner.
\end{abstract}

Results: $23.9 \%$ met criteria for depressive symptoms. A higher proportion of females than males (20.8\% vs. $7.6 \%$ ) reported ever being afraid of a partner during their lifetime (OR 3.2, 95\% 2.5 to 4.0) and a lower proportion of females (12\%) than males (25\%) were hazardous drinkers (OR 0.4; 95\%Cl 0.4 to 0.5 ); and a higher proportion of females than males (20.8\% vs. $7.6 \%)$ reported ever being afraid of a partner during their lifetime $(\mathrm{OR} 3.2,95 \% \mathrm{Cl} 2.5$ to 4.0). Men and women who had ever been afraid of a partner or who were hazardous drinkers had on average higher depressive symptom scores than those who had never been afraid or who were not hazardous drinkers. There was a stronger association between depressive symptoms and ever been afraid of a partner compared to hazardous drinking for both males (ever afraid of partner; Diff 6.87; 95\% Cl 5.42, 8.33; $p<0.001$ vs. hazardous drinking in last year; Diff 1.07, 95\% Cl 0.21, 1.94; $\mathrm{p}=0.015$ ) and females (ever afraid of partner; Diff 5.26; 95\% Cl 4.55, 5.97; $p<0.001$ vs. hazardous drinking in last year; Diff 2.23, 95\% Cl 1.35, 3.11; $p<0.001$ ), even after adjusting for age group, income, employment status, marital status, living alone and education level.

Conclusions: Strategies to assist primary care doctors to recognise and manage intimate partner violence and hazardous drinking in patients with depression may lead to better outcomes from management of depression in primary care.

\section{Background}

Depressive symptoms,[1] hazardous drinking [2] and intimate partner violence (IPV) [3] are common among patients attending general practice. In a recent study of primary care patients in six countries, $24-55 \%$ met criteria for current depressive symptoms [4]. A recent Australian report estimated that after adjusting for age-sex

\footnotetext{
* Correspondence: ggilchrist@imim.es

'Substance Use Disorders Research Group, Neuropsychopharmacology Programme; Institut Municipal d'Investigació Mèdica (IMIM)-Hospital del Mar, Barcelona, Spain

Full list of author information is available at the end of the article
}

attendance patterns, $29 \%$ of the Australian general practice population was consuming alcohol at a level placing them "at-risk", with a greater proportion of males (36\%) at risk than females (24\%) [5]. Around a quarter of female general practice patients in Australia have experienced some type of abuse in an adult intimate relationship, with up to $30 \%$ having ever been afraid of their partner [3,6]. The prevalence of IPV among male general practice patients has not been documented. Although these problems frequently coexist, the relationship has not been fully explored. 
Alcohol and IPV are relatively independent risk factors for depression. Both men and women with a history of depression and men with a history of alcohol dependence are more likely to experience abuse in relationships [7]. IPV may lead to depression among women but not in men; and to alcohol abuse among men but not women [7]. Moreover, hazardous drinking may be a way of coping with or "self-medicating" the negative experience of IPV or depression [8]. A feminist perspective, adopted in the current study, supports the possibility that depression and hazardous drinking are consequences of IPV for women, rather than risk factors for women becoming victims $[9,10]$.

General practitioners (GPs) often lack confidence in detecting and managing hazardous drinking and IPV, particularly the latter $[3,11-15]$. However, research demonstrates that systematically screening general practice patients for alcohol use and providing brief interventions is cost effective and reduces alcohol consumption [16-18]. Although there is insufficient evidence to support the introduction of routine screening for IPV in general practice,[19] enquiring about fear of a partner/ex-partner is receiving increased attention $[20,21]$ and has significant potential as a stand alone screening item [20].

Hazardous drinking and alcohol disorders are associated with depression,[22] with one study reporting the odds of heavy drinking primary care patients meeting criteria for a major depressive disorder were twice that of non heavy drinking patients [23]. In a US study of primary care patients with probable current depressive disorder, $8 \%$ of women and $19 \%$ of men reported hazardous drinking [24]. While men consistently report higher levels of alcohol related disorders than women; women with alcohol related disorders consistently report a higher prevalence of depressive disorders than men with alcohol related disorders,[25] potentially related to the higher prevalence of sexual or physical abuse experienced by women $[26,27]$. Patients with alcohol problems $[22,28,29]$ report poorer outcomes from depression. Higher rates of general practice attendance have been reported among those with alcohol dependence and an additional comorbid psychiatric (mainly affective) disorder compared to those with alcohol dependence alone [29]. Victims of IPV place a great burden on primary care services [30]. Therefore, it is important that GPs identify and address both these psychosocial issues in the course of their depression management, not just alcohol use.

IPV is associated with depression and with alcohol use in several populations. A meta analysis reported the weighted mean prevalence of $44 \%$ for depression and $19 \%$ for alcohol abuse or dependence among women who reported experiencing IPV in general population and general practice settings [9]. In a cross sectional study of over 1000 consecutive female patients attending general practice in Australia, females who reported IPV were more likely to meet criteria for depressive symptoms (e.g. for severe combined abuse, OR 8.0, 95\% CI 4.8 to 13.0) [3]. Among female patients in healthcare settings including primary care, the odds of having experienced IPV in the past year were 2.40 for problem drinking women compared to non-problem drinkers [31]. Furthermore, several studies report an exposure response, with alcohol consumption increasing following IPV [32] to cope with the abuse [8,33,34]. Baseline findings from the current study conducted in Australian general practice highlight that having a substance abuse disorder and reporting ever being afraid of any partner were both associated with persistent depressive symptoms [35].

Despite the high prevalence of these three problems in patients attending general practice; the relationship between depressive symptoms, fear of partner and hazardous drinking remains relatively unexplored. Separate community campaigns focus on each of these major public health problems; however, in clinical practice and education of GPs, IPV has not received the same attention as depression and alcohol related problems [36]. The relationship between depression and hazardous drinking is well understood especially in men; however, the relationship between IPV and depression is less well recognised. While most patients with any or all of these problems are managed in general practice, existing research focuses on patients in psychiatric inpatient settings [1,22] and victims of IPV in shelters [37].

This paper explores the association between depressive symptoms, ever being afraid of a partner and hazardous drinking using cross-sectional data from the diamond cohort, a large primary care cohort study underway in Australia [35]. Our objective is to specifically explore if fear of partner (IPV) is as closely associated with depressive symptoms as hazardous drinking. Our hypothesis was that IPV would be more strongly associated with depression than hazardous drinking.

\section{Methods}

Ethics approval was granted by the University of Melbourne's Human Research Ethics Committee (\# 030613).

\section{Design and setting}

diamond is a prospective longitudinal cohort study of 789 randomly recruited patients with depression from 30 randomly recruited metropolitan and rural general practices in Victoria, Australia [35,38]. This paper reports on data collected at the screening stage of the study using cross sectional data only. Briefly, 17,780 randomly selected patients from 30 general practices who 
had attended their GP in the previous 12 months for any reason were sent a screening survey between January and December 2005.

\section{Patient screening survey}

The patient screening survey included questions on demographics, lifestyle, health and well-being.

The 20-item Center for Epidemiological Studies Depression Scale (CES-D) measured depressive symptomatology in the previous week [39]. Scores range from 0 to 60 with higher scores indicating more symptoms. A score of $\geq 16$ indicates a significant level of depressive symptomatology and identifies a group of patients experiencing major and minor depression and dysthymia (hereafter reported as depressive symptoms). The CES-D has good reliability and validity [39].

The Fast Alcohol Screening Test (FAST) [40] measured hazardous drinking in the past 12 months, i.e. " $a$ pattern of drinking that is associated with a high risk of psychosocial or physical problems in the future" [41]. The FAST has four items from which a total score ranging from 0 to 16 is generated. A score of $\geq 3$ indicates hazardous drinking in the past 12 months. The four items, originally from the Alcohol Use Disorders Identification Test (AUDIT) [42] cover 1) the frequency of having six (four for women) or more drinks on one occasion; 2) the frequency of being unable to remember what happened the night before because you had been drinking; 3) the frequency of failing to do what was normally expected of you because of drinking; and 4) whether a relative or friend, or a doctor or other health worker had been concerned about your drinking or suggested you cut down. When sensitivity and specificity were tested against the AUDIT, [42] the FAST was reliable across age, sex and location [40]. Good reliability was demonstrated in the intercorrelations between the four items in the FAST (Chronbach's alpha $=0.77)$ and in the test-retest (Test-retest reliability $=0.81)$.

Patients were asked whether they had ever been afraid of any intimate partner to determine probable IPV, a question that correlates well with the severe combined abuse dimension of the Composite Abuse Scale (assessment of IPV) among female general practice patients [43]. Asking whether a patient has ever been afraid of any partner has been shown to have good sensitivity and specificity for identifying women who have experienced physical abuse $(75.5 \%$ sensitivity, $82.4 \%$ specificity) and/or severe combined physical and sexual abuse (85.0\% sensitivity, $77.7 \%$ specificity) in a large sample of women attending family physicians for primary care. It does not perform as well in identifying women who have experienced emotional abuse alone $(60.6 \%$ sensitivity, $80.4 \%$ specificity) [44].
Patients self-rated their overall health as poor/fair/ good/excellent, using a question from the Short Form 12 (SF-12),[45] a well validated measure of physical and psychological functioning. Patients were also asked whether they had any long-term illness, health problem or disability that limited their daily activities or the work they could do (including problems related to aging).

\section{Statistical methods}

The outcome measure was CES-D score and was summarised as means and standard deviations (SD) for each of the demographic and psychosocial factors. Confidence intervals and $\mathrm{p}$-values reported were adjusted for the clustering effect of participants nested within general practices. Marginal logistic regression using generalised estimating equations with robust standard errors was used to examine the association between hazardous drinking and sex and probable IPV and sex. Results are reported as odds ratios (OR) with respective 95\% confidence intervals $(95 \% \mathrm{CI})$.

Mixed effects linear regression model using restricted maximum likelihood estimation (REML), treating GP practice as a random effect, was used to examine the association between CES-D score and each factor. The results were reported as differences in mean outcome between individuals with and without the factor, with respective $95 \% \mathrm{CI}$ and $\mathrm{p}$-values. Interaction was tested between males and females and each of the patient factors. The significance level for testing interaction between factors was set at $10 \%$. When the p-value for interaction was $\geq 10 \%$, the analysis was reported separately by sex. Analysis to explore the association between depressive symptoms, hazardous drinking and ever being afraid of a partner was performed separately by sex.

Multivariable mixed effects linear regression models (REML) were used to test for interaction between hazardous drinking and ever being afraid of partner. Ever afraid of partner and hazardous drinking were fitted in the same model adjusted for all factors with the exception of sexuality: age group, education level, employment status, pension or benefit as main source of income, marital status, lives alone. Sexuality was not adjusted for due to the large proportion of missing data in the sample. Data were analysed using Stata, version $10.1[46]$.

\section{Results}

Forty-three percent $(7667 / 17780,43.1 \%)$ of patients returned a screening survey. Patients who returned the survey were on average older (50.9 years (SD, 14.2) vs. 46.2 years $(\mathrm{SD}, 15.3)$ ) and more likely to be female $(66.5 \%$ vs. $60.7 \%)$ than those who did not return the 
Table 1 Depressive symptoms by patient characteristics and test for interaction for patient characteristics and sex

\begin{tabular}{|c|c|c|c|c|c|c|c|c|}
\hline & $\mathrm{N}$ & Mean & (SD) & Diff & $(95 \% \mathrm{Cl})$ & P-value & Interaction term & P-value \\
\hline \multicolumn{9}{|l|}{ Gender } \\
\hline Male & 2491 & 9.76 & (10.08) & Ref & & & & \\
\hline Female & 4991 & 10.9 & $(10.53)$ & 1.03 & $(0.51,1.54)$ & $<0.001$ & & \\
\hline \multicolumn{9}{|l|}{ Age group (Years) } \\
\hline $18-24$ & 323 & 14.4 & $(11.44)$ & Ref & & & & 0.18 \\
\hline $25-34$ & 842 & 12.54 & $(10.82)$ & -1.84 & $(-3.15,-0.52)$ & $<0.001$ & -3.39 & \\
\hline $35-44$ & 1443 & 11.15 & $(10.88)$ & -3.10 & $(-4.34,-1.86)$ & & -2.88 & \\
\hline $45-54$ & 1763 & 10.83 & $(10.90)$ & -3.47 & $(-4.69,-2.25)$ & & -2.50 & \\
\hline $55-64$ & 1694 & 9.67 & $(9.95)$ & -4.59 & $(-5.81,-3.36)$ & & -3.02 & \\
\hline $65-75$ & 1361 & 8.37 & $(8.48)$ & -5.87 & $(-7.12,-4.61)$ & & -1.68 & \\
\hline \multicolumn{9}{|l|}{ Ever afraid of partner } \\
\hline Not ever afraid & 6042 & 9.23 & $(9.36)$ & Ref & & & & \\
\hline Ever afraid of partner & 1202 & 16.49 & $(12.55)$ & 7.14 & $(6.52,7.76)$ & $<0.001$ & -2.5 & 0.003 \\
\hline \multicolumn{9}{|l|}{ Hazardous drinking } \\
\hline No & 6218 & 10.01 & $(10.09)$ & Ref & & & & \\
\hline Yes & 1228 & 12.93 & $(11.42)$ & 2.97 & $(2.34,3.60)$ & $<0.001$ & 1.41 & 0.03 \\
\hline \multicolumn{9}{|l|}{ Current smoker } \\
\hline No & 6107 & 9.55 & $(9.56)$ & Ref & & & & \\
\hline Yes & 1357 & 14.76 & $(12.58)$ & 5.12 & $(4.52,5.72)$ & $<0.001$ & -1.1 & 0.09 \\
\hline \multicolumn{9}{|l|}{ Marital status } \\
\hline Never married/single & 1334 & 13.46 & $(11.63)$ & Ref & & $<0.001$ & & 0.01 \\
\hline Widowed/divorced/aaseparated & 1312 & 13.38 & $(12.28)$ & -0.11 & $(-0.88,0.66)$ & & -1.37 & \\
\hline Married & 4770 & 8.9 & $(9.04)$ & -4.51 & $(-5.14,-3.89)$ & & 0.82 & \\
\hline \multicolumn{9}{|l|}{ Sexuality } \\
\hline Exclusively heterosexual & 6803 & 10.16 & $(10.21)$ & Ref & & & & \\
\hline Not exclusively heterosexual & 354 & 14.65 & $(11.76)$ & 4.44 & $(3.31,5.57)$ & $<0.001$ & 2.35 & 0.05 \\
\hline \multicolumn{9}{|l|}{ Lives alone } \\
\hline No & 6476 & 10.11 & $(10.05)$ & Ref & & & & \\
\hline Yes & 996 & 13.17 & $(12.05)$ & 3.09 & $(2.40,3.78)$ & $<0.001$ & -3.82 & $<0.001$ \\
\hline \multicolumn{9}{|l|}{ Employment status } \\
\hline Employed/Student & 4802 & 9.93 & $(9.87)$ & Ref & & $<0.001$ & & 0.75 \\
\hline Not employed/not in paid employment & 2274 & 9.89 & $(9.72)$ & 0.07 & $(-0.44,0.57)$ & & -0.06 & \\
\hline Unable to work & 401 & 20.85 & $(13.85)$ & 11.01 & $(9.98,12.04)$ & & 0.77 & \\
\hline \multicolumn{9}{|l|}{ Highest level of education } \\
\hline Completed year 12 or less & 4182 & 11.07 & $(10.57)$ & Ref & & $<0.001$ & & 0.57 \\
\hline Certificate or diploma & 1566 & 10.53 & $(10.64)$ & -0.71 & $(-1.31,-0.11)$ & & 0.65 & \\
\hline Bachelor degree or higher & 1718 & 9.1 & $(9.52)$ & -2.18 & $(-2.79,-1.57)$ & & 0.41 & \\
\hline \multicolumn{9}{|l|}{$\begin{array}{l}\text { Pension or benefit main } \\
\text { source of income }\end{array}$} \\
\hline No & 5518 & 9.6 & $(9.60)$ & Ref & & & & \\
\hline Yes & 1890 & 13.11 & (12.06) & 3.62 & $(3.08,4.16)$ & $<0.001$ & -0.28 & 0.62 \\
\hline \multicolumn{9}{|l|}{ GP location } \\
\hline Urban (RRMA 1 \& 2) & 5063 & 10.56 & $(10.46)$ & Ref & & & & \\
\hline Rural (RRMA 3-5) & 2433 & 10.42 & $(10.22)$ & -0.14 & $(-1.22,0.95)$ & 0.81 & -0.55 & 0.32 \\
\hline \multicolumn{9}{|l|}{ Country of birth } \\
\hline Other & 1384 & 10.51 & $(10.20)$ & Ref & & & -0.11 & 0.86 \\
\hline Australia & 6093 & 10.53 & $(10.43)$ & 0.11 & $(-0.50,0.72)$ & 0.72 & & \\
\hline \multicolumn{9}{|l|}{$\begin{array}{l}\text { Long term illness/health } \\
\text { problem or disability }\end{array}$} \\
\hline No & 4964 & 8.81 & $(9.06)$ & Ref & & & & \\
\hline Yes & 2363 & 14.06 & $(12.00)$ & 5.33 & $(4.83,5.82)$ & $<0.001$ & -1.64 & 0.002 \\
\hline
\end{tabular}

Health rating 
Table 1: Depressive symptoms by patient characteristics and test for interaction for patient characteristics and sex (Continued)

\begin{tabular}{lccccccc}
\hline Excellent & 763 & 5.4 & $(6.79)$ & Ref & & $<0.001$ & 0.05 \\
Very good & 2782 & 7.37 & $(7.69)$ & 2.04 & $(1.28,2.78)$ & & 1.53 \\
Good & 2644 & 11.54 & $(10.00)$ & 6.18 & $(5.42,6.94)$ & 2.07 & 0.37 \\
Fair & 1012 & 17.19 & $(12.28)$ & 11.9 & $(11.02,12.79)$ & 1.83 \\
Poor & 206 & 25 & $(14.18)$ & 19.6 & $(18.19,21.08)$ & & \\
\hline
\end{tabular}

Ref $=$ reference category for patient characteristics

$\mathrm{SD}=$ Standard deviation

Difference in mean depressive symptoms (Diff), respective $95 \%$ confidence intervals $(\mathrm{Cl})$ and p-values calculated using mixed effects linear regression using restricted maximum likelihood estimation (REML), treating GP practice as a random effect

Interaction term for each patient characteristic and sex and related p-value

survey. No further data were available for comparison between those who returned their survey and those who did not.

Sixty-four percent were married (4866/7580), 63\% were employed or students (4792/7639) and 37\% (2847/ 7639) were not in employment or were unable to work. The mean age was 50.9 years (SD 14.2).

The mean age of all 17780 patients (60.7\% female) sent a screening survey was 46.2 years (SD 15.3). Therefore, patients who completed the screening survey were older and more likely to be female [35].

\section{Emotional well-being}

Overall, 23.9\% (1793/7509) scored CES-D $\geq 16$ indicating a significant level of depressive symptoms, $21.5 \%$ $(538 / 2498)$ of male and $25.1 \%(1252 / 4997)$ of female patients.

\section{Hazardous drinking}

Almost 15\% (752/5061, 14.9\%) of females and 28.5\% $(722 / 2533)$ of males reported drinking six or eight standard drinks respectively on one occasion at least monthly; with $6.8 \%(342 / 5061)$ of females and $18 \%$ (457/2533) of males reporting doing so at least once a week. Over $16.4 \%$ (1245/7602; 95\%CI 14.6 to 18.1$)$ met criteria for hazardous drinking in the past 12 months. Fewer females $(12.1 \%, 611 / 5056)$ compared to males $(25.0 \%, 633 / 2532)$ were hazardous drinkers (OR 0.4; 95\%CI 0.4 to 0.5$)$. Almost a third (394/1772, 32.1\%) of hazardous drinkers scored CES-D $\geq 16$ compared to $22.1 \%(1378 / 6230)$ who were not hazardous drinkers.

\section{Ever afraid of intimate partner}

For individuals who had ever been in an intimate relationship, 16.4\% (1213/7372) reported ever being afraid of their partner. A higher proportion of females (1029/4938, $20.8 \%)$ compared to males $(183 / 2419,7.6 \%)$ reported ever being afraid of an intimate partner during their lifetime (OR 3.2, 95\%CI 2.5 to 4.0). Forty-five percent (536/ $1203,44.6 \%)$ of participants who had ever been afraid of their partner had depressive symptoms (CES-D $\geq 16$ ), in contrast to $19.5 \%(1179 / 6051)$ of participants that had never been afraid of an intimate partner.

\section{Psychosocial factors associated with CES-D score}

Table 1 shows strong evidence for an association between depressive symptoms and most of the patient factors, except general practice location and patient's country of birth. The results for these patient factors are reported by sex in Table 2 . Table 2 shows that men and women who had ever been afraid of a partner, or who were hazardous drinkers, had on average higher depressive symptom scores than those who had never been afraid, or who were not hazardous drinkers.

\section{Association between depressive symptoms, hazardous drinking and ever been afraid of partner}

Table 3 presents the multivariable model for depressive symptoms where both hazardous drinking and IPV were fitted to the same model for males and females separately. There was stronger association between depressive symptoms and ever being afraid of a partner compared to depressive symptoms and hazardous drinking (Table 3, Model 1). Test for interaction showed no evidence for an interaction between hazardous drinking and ever been afraid of partner for both sexes (interaction term $=-2.33,95 \% \mathrm{CI}:-5.4,0.75, \mathrm{p}$-value $=0.14$ for males and $0.02,95 \% \mathrm{CI}:-1.9,1.9, \mathrm{p}$-value $=0.98$ for females). A small proportion of participants reported positive for hazardous drinking and ever being afraid of intimate partner $(2.63 \%(63 / 2391)$ of males and 3.94\% (194/4919) of females). The strength of association between depressive symptoms and ever been afraid of a partner, and depressive symptoms and hazardous drinking remained after adjusting for all factors except sexuality (Table 3, model 2).

\section{Discussion}

\section{Summary of main findings}

Almost a quarter of participants randomly recruited from general practice met criteria for current depressive 
Table 2 Depressive symptoms by patient characteristics separately for males and females

\begin{tabular}{|c|c|c|c|c|c|c|}
\hline \multicolumn{7}{|c|}{ Males $(\mathrm{N}=2491)$} \\
\hline & $\mathbf{n}$ & Mean & (SD) & Diff & $(95 \% \mathrm{Cl})$ & P-value \\
\hline \multicolumn{7}{|l|}{ Ever afraid of partner } \\
\hline Not ever afraid & 2185 & 8.88 & $(9.28)$ & Ref & & \\
\hline Ever afraid of partner & 179 & 18.23 & $(12.61)$ & 9.17 & $(7.66,10.69)$ & $<0.001$ \\
\hline \multicolumn{7}{|l|}{ Hazardous drinking } \\
\hline No & 1841 & 9.09 & $(9.62)$ & Ref & & \\
\hline Yes & 620 & 11.52 & $(11.02)$ & 2.51 & $(1.58,3.45)$ & $<0.001$ \\
\hline \multicolumn{7}{|l|}{ Current smoker } \\
\hline No & 2051 & 8.73 & $(8.98)$ & Ref & & \\
\hline Yes & 430 & 14.73 & $(13.14)$ & 5.84 & $(4.78,6.89)$ & $<0.001$ \\
\hline \multicolumn{7}{|l|}{ Marital status } \\
\hline Never married/single & 423 & 13.16 & $(11.92)$ & & & $<0.001$ \\
\hline Widowed/divorced/separated & 321 & 14.09 & $(12.42)$ & 0.89 & $(-0.59,2.37)$ & \\
\hline Married & 1729 & 8.1 & (8.55) & -5.03 & $(-6.13,-3.94)$ & \\
\hline \multicolumn{7}{|l|}{ Sexuality } \\
\hline Exclusively heterosexual & 2240 & 9.4 & $(9.90)$ & Ref & & \\
\hline Not exclusively heterosexual & 147 & 12.76 & $(11.12)$ & 3.07 & $(1.26,4.88)$ & 0.001 \\
\hline \multicolumn{7}{|l|}{ Live alone } \\
\hline No & 2171 & 9.03 & $(9.41)$ & Ref & & \\
\hline Yes & 314 & 14.74 & $(12.76)$ & 5.67 & $(4.45,6.89)$ & $<0.001$ \\
\hline \multicolumn{7}{|l|}{$\begin{array}{l}\text { Long term illness/health } \\
\text { problem or disability }\end{array}$} \\
\hline No & 1405 & 7.08 & $(7.52)$ & Ref & & \\
\hline Yes & 1021 & 13.62 & $(11.90)$ & 6.57 & $(5.76,7.38)$ & $<0.001$ \\
\hline \multicolumn{7}{|l|}{ Health rating } \\
\hline Excellent & 205 & 4.9 & $(6.05)$ & Ref & & $<0.001$ \\
\hline Very good & 808 & 5.84 & $(6.32)$ & 0.94 & $(-0.49,2.37)$ & \\
\hline Good & 962 & 9.86 & $(9.17)$ & 4.89 & $(3.48,6.30)$ & \\
\hline Fair & 397 & 16.58 & $(12.18)$ & 11.71 & $(10.13,13.28)$ & \\
\hline Poor & 92 & 23.64 & $(13.46)$ & 18.66 & $(16.35,20.96)$ & \\
\hline \multicolumn{7}{|c|}{ Females $(\mathrm{N}=4991)$} \\
\hline & $\mathbf{n}$ & Mean & (SD) & Diff & $(95 \% \mathrm{Cl})$ & P-value \\
\hline \multicolumn{7}{|l|}{ Ever afraid of partner } \\
\hline Not ever afraid & 3845 & 9.44 & $(9.40)$ & Ref & & \\
\hline Ever afraid of partner & 1022 & 16.19 & $(12.52)$ & 6.67 & $(5.99,7.36)$ & $<0.001$ \\
\hline \multicolumn{7}{|l|}{ Hazardous drinking } \\
\hline No & 4364 & 10.41 & $(10.27)$ & Ref & & \\
\hline Yes & 608 & 14.38 & $(11.65)$ & 3.93 & $(3.05,4.80)$ & $<0.001$ \\
\hline \multicolumn{7}{|l|}{ Current smoker } \\
\hline No & 4043 & 9.98 & $(9.82)$ & Ref & & \\
\hline Yes & 926 & 14.78 & $(12.33)$ & 4.74 & $(4.01,5.47)$ & $<0.001$ \\
\hline \multicolumn{7}{|l|}{ Marital status } \\
\hline Never married/single & 911 & 13.61 & $(11.50)$ & & & $<0.001$ \\
\hline Widowed/divorced/separated & 991 & 13.15 & $(12.23)$ & -0.48 & $(-1.40,0.43)$ & \\
\hline Married & 3040 & 9.36 & $(9.27)$ & -4.22 & $(-4.97,-3.46)$ & \\
\hline \multicolumn{7}{|l|}{ Sexuality } \\
\hline Exclusively heterosexual & 4563 & 10.53 & $(10.33)$ & Ref & & \\
\hline Not exclusively heterosexual & 207 & 15.99 & $(12.03)$ & 5.41 & $(3.98,6.84)$ & $<0.001$ \\
\hline \multicolumn{7}{|l|}{ Live alone } \\
\hline No & 4304 & 10.66 & $(10.32)$ & Ref & & \\
\hline Yes & 682 & 12.44 & $(11.65)$ & 1.85 & $(1.02,2.68)$ & $<0.001$ \\
\hline
\end{tabular}


Table 2: Depressive symptoms by patient characteristics separately for males and females (Continued)

\begin{tabular}{|c|c|c|c|c|c|}
\hline \multicolumn{6}{|c|}{$\begin{array}{l}\text { Long term illness/health } \\
\text { problem or disability }\end{array}$} \\
\hline No & 3552 & $9.5 \quad(9.53)$ & Ref & & \\
\hline Yes & 1336 & 14.42 (12.08) & 4.93 & $(4.30,5.57)$ & $<0.001$ \\
\hline \multicolumn{6}{|l|}{ Health rating } \\
\hline Excellent & 557 & $5.58 \quad(7.05)$ & Ref & & $<0.001$ \\
\hline Very good & 1969 & 7.99 (8.11) & 2.47 & $(1.59,3.35)$ & \\
\hline Good & 1677 & $12.51 \quad(10.33)$ & 6.96 & $(6.06,7.86)$ & \\
\hline Fair & 612 & $17.61 \quad$ (12.36) & 12.08 & $(11.01,13.15)$ & \\
\hline Poor & 114 & $26.1 \quad(14.71)$ & 20.48 & $(18.60,22.37)$ & \\
\hline
\end{tabular}

Ref = reference category for patient characteristics

SD = Standard deviation

Difference in mean depressive symptoms (Diff), respective $95 \%$ confidence intervals $(\mathrm{Cl})$ and p-values calculated using mixed effects linear regression using restricted maximum likelihood estimation (REML), treating GP practice as a random effect

Analysis reported separately for males and females when p-value for interaction was $10 \%$ or greater in Table 1

symptoms (24\%). IPV (16\%) and hazardous drinking (16\%) were equally common among patients in the current study.

Men and women who had ever been afraid of a partner or who were hazardous drinkers had on average higher depressive symptom scores than those who had never been afraid or who were not hazardous drinkers. There was a stronger association between depressive symptoms and ever been afraid of a partner compared to hazardous drinking for both males and females, even after adjusting for age group, income, employment status, marital status, living alone and education level.

IPV and hazardous drinking are serious problems in themselves and are also known to complicate the detection and management of depression in primary care. We do not know whether outcomes for men and women with depression differ for those experiencing one or both of these problems but we are tracking this in the diamond study and will report in due course.

\section{Comparison with existing literature}

A recent Australian report found considerably higher proportions of male (36\%) and female (24\%) patients drinking heavily than the current study [47]. However, that study had a lower threshold for heavy drinking than the current study (i.e. drinking six or more standard drinks for men (four or more for women) on one occasion at least once a week). Furthermore, it may not be representative of the population who attend general practice in Australia as, unlike the current study; it was biased towards frequent attenders.

Almost a quarter of patients met criteria for depressive symptoms. As expected, these figures are lower than studies where primary care patients are screened in

Table 3 Multivariable analysis for Hazardous drinking in last year and ever-afraid of partner

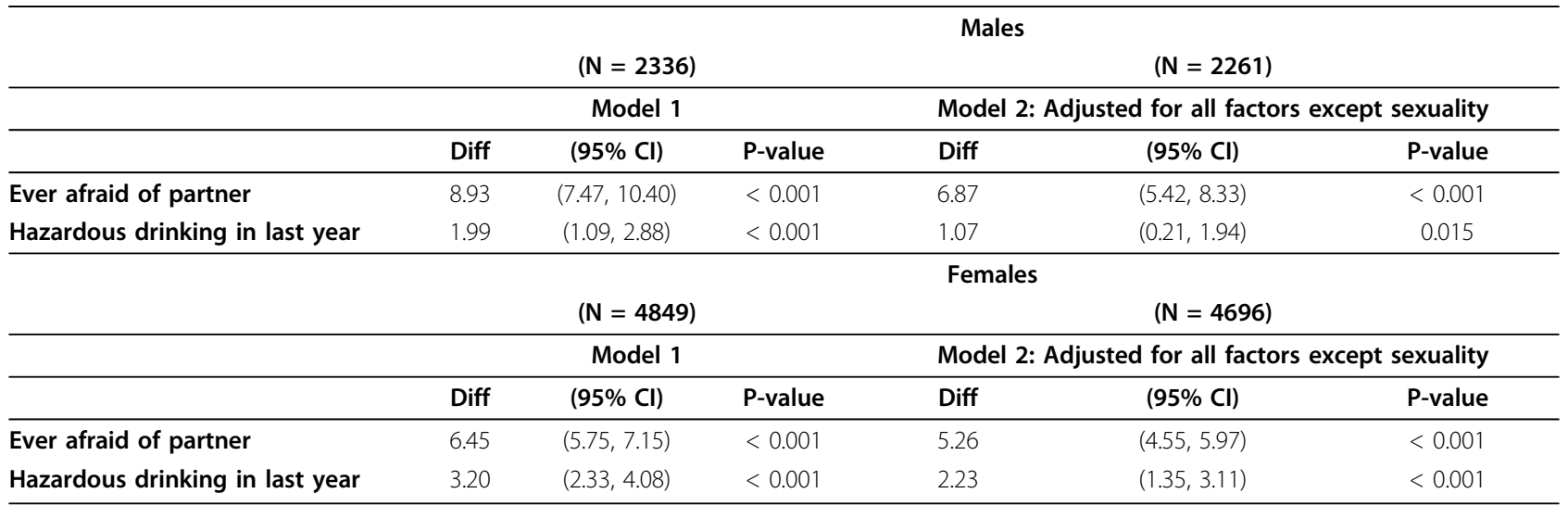

Model 1 - Adjusted model - Ever afraid of partner and hazardous drinking fitted in the same model, but not adjusted for any other

Model 2 - Adjusted for all factors, except sexuality - Ever afraid of partner and hazardous drinking fitted in the same model adjusted for all factors: Age group, education level, employment status, pension or benefit as main source of income, marital status, live alone, but not sexuality due to large proportion of missing data

Difference in mean depressive symptoms (Diff), respective 95\% confidence intervals (CI) and p-values calculated using mixed effects linear regression using restricted maximum likelihood estimation (REML), treating GP practice as a random effect 
waiting rooms using the CES-D (37\% overall (range 24\%-55\% across countries)). Contributing factors may be that patients in waiting rooms are more likely to be experiencing an acute illness and also that patients with depressive symptoms are high utilizers of primary care services and therefore may be more likely to be recruited into studies that recruit in waiting rooms due to frequent attendance.

Our results on the incidence of potential partner abuse among females are similar to those reported in an Australian study among female patients in general practice waiting rooms [3]. No data are available for comparison among male patients.

\section{Implications for future research or clinical practice}

GPs detect IPV in less than a fifth of female patients experiencing it [48]. GPs play a vital role in the identification and treatment of alcohol problems [24] and it has been argued that they need to play a greater role in IPV, [3] particularly when patients present with depressive symptoms. Duxbury suggests that GPs should enquire about IPV among patients presenting with associated psychological conditions to improve detection [49]. While Feder et al. [50] remind us that not all patients experiencing IPV present with such psychological symptoms, [3] we believe that GPs should enquire about fear of partner and hazardous drinking in patients presenting with depressive symptoms. Strategies to assist primary care doctors to recognise and manage intimate partner violence and hazardous drinking in patients with depression may lead to better outcomes from management of depression in primary care.

We know that GPs can provide effective brief interventions to reduce alcohol consumption,[51] however, there is a lack of evidence around IPV interventions $[37,52,53]$. We have highlighted the great need for those patients attending with depression to have the opportunity and encouragement to discuss both alcohol use and relationship problems to determine whether associated social or clinical problems require attention as part of the management of depression [54].

\section{Strengths and limitations of the study}

A major strength of this study was the large sample size that enabled testing of interactions between males and females, and separate reporting of results for men and women. This cross-sectional sample has shown the strength of association between hazardous drinking, ever been afraid of their partner and depressive symptoms. The findings presented are limited as causality cannot be implied due to the cross sectional nature of the data. The number of patients with both hazardous drinking and being afraid of partner were small. A small proportion of participants reported positive for hazardous drinking and ever being afraid of intimate partner (63 males and 194 females), so it was not possible to test for the interaction between hazardous drinking and reporting being afraid of partner.

\section{Conclusions}

Being afraid of your partner and hazardous drinking are both associated with depressive symptoms. Yet not everyone who has depressive symptoms will report hazardous drinking or fear of their partner; some will report none, some one and a few, both of these. It is likely that the association with depressive symptoms is bi-directional for both these important problems and our paper highlights the complex relationships with depressive symptoms as they present in primary care. The strong association found in our sample highlights the need to investigate whether interventions designed to assist in recognising and managing these problems results in better outcomes than treating depressive symptoms alone.

\section{Acknowledgements}

The diamond study was funded by the National Health and Medical Research Council (ID 299869 \& 454463) and the Victorian Centre for Excellence in Depression and Related Disorders, an initiative between beyondblue and the State Government of Victoria. We wish to thank the diamond project team, including the associate investigators and researchers involved in the study: Ms Darshini Ayton, Ms Vanessa Madden, Dr David Pierce, Ms Maria Potiriadis, Ms Melina Ramp, Dr Lena Sanci, Dr Jane Sims, Ms Donna Southern and the casual research staff. We acknowledge the thirty dedicated GPs, their patients and practice staff for making this research possible.

\section{Author details}

'Substance Use Disorders Research Group, Neuropsychopharmacology Programme; Institut Municipal d'Investigació Mèdica (IMIM)-Hospital del Mar, Barcelona, Spain. ${ }^{2}$ Primary Care Research Unit, Department of General Practice, The University of Melbourne, Melbourne, Australia. ${ }^{3}$ Orygen Youth Health Research Centre, The University of Melbourne, Melbourne, Australia.

\section{Authors' contributions}

JG conceived of the diamond study \& all authors contributed to its design. PC analysed \& interpreted the data. GG \& KH drafted the manuscript and all authors contributed to its revision. All authors approved the final version of the article to be published.

\section{Competing interests}

The authors declare that they have no competing interests.

Received: 30 March 2010 Accepted: 27 September 2010 Published: 27 September 2010

\section{References}

1. Gilchrist G, Gunn J: Observational studies of depression in primary care: what do we know? BMC Fam Pract 2007, 8:28.

2. Fiellin DA, Reid MC, O'Connor PG: Screening for Alcohol Problems in Primary Care. A Systematic Review. Arch Intern Med 2000, 160:1977-1989.

3. Hegarty K, Gunn J, Chondros P, Small R: Association between depression and abuse by partners of women attending general practice: descriptive, cross sectional survey. BMJ 2004, 328:621-624.

4. Herrman H, Patrick DL, Diehr P, Martin ML, Fleck M, Simon GE, et al: Longitudinal investigation of depression outcomes in primary care in six 
countries: the LIDO study. Functional status, health service use and treatment of people with depressive symptoms. Psychol Med 2002, 32:889-902.

5. Britt H, Miller GC, Charles J, Henderson J, Bayram C, Harrison C, et al: General practice activity in Australia 2007-08 Canberra: Australian Institute of Health and Welfare 2008, AlHW Catalogue No. GEP 22.

6. Mazza D, Dennerstein L, Ryan V: Physical, sexual and emotional violence against women: a general practice-based prevalence study. Med J Aust 1996, 164:14-17.

7. Ehrensaft MK, Moffitt TE, Caspi A: Is Domestic Violence Followed by an Increased Risk of Psychiatric Disorders Among Women But Not Among Men? A Longitudinal Cohort Study. Am J Psychiat 2006, 163:885-92.

8. Wingood GM, DiClemente RJ, Raj A: Adverse consequences of intimate partner abuse among women in non-urban domestic violence shelters. Am J Prev Med 2000, 119:183-192.

9. Golding JM: Intimate partner violence as a risk factor for mental disorders: a meta-analysis. J Fam Viol 1999, 14:99-132.

10. Campbell JC: Health consequences of intimate partner violence. Lancet 2002, 359:1331-6.

11. McCambridge J, Platts S, Whooley D, Strang J: Encouraging GP alcohol intervention: pilot study of change-orientated reflective listening (CORL). Alc Alcoholism 2004, 39:146-149.

12. Taft A, Broom DH, Legge D: General practitioner management of intimate partner abuse and the whole family: qualitative study. BMJ 2004, 28:618-621.

13. Proude EM, Britt H, Valenti L, Conigrave KM: The relationship between selfreported alcohol intake and the morbidities managed by GPs in Australia. BMC Fam Pract 2006, 7:17.

14. Proude EM, Conigrave KM, Haber PS: Effectiveness of skills-based training using the Drink-less package to increase family practitioner confidence in intervening for alcohol use disorders. BMC Med Educ 2006, 6:8.

15. Miller $D$, Jaye $C: G P s^{\prime}$ perception of their role in the identification and management of family violence. Fam Pract 2007, 24:95-101.

16. Kraemer KL: The cost-effectiveness and cost-benefit of screening and brief intervention for unhealthy alcohol use in medical settings. Subst Abuse 2007, 28:67-77.

17. Babor TF, McRee BG, Kassebaum PA, Grimaldi PL, Ahmed K, Bray J: Screening, Brief Intervention, and Referral to Treatment (SBIRT): toward a public health approach to the management of substance abuse. Subst Abuse 2007, 28:7-30.

18. Bertholet MD, Daeppen J, Wietlisbach V, Fleming M, Burnand B: Reduction of alcohol consumption by brief alcohol intervention in primary care systematic review and meta-analysis. Arch Intern Med 2005, 165:986-995.

19. Feder G, Ramsay J, Dunne D, Rose M, Arsene C, Norman R, et al: How Far Does Screening Women for Domestic (Partner) Violence in Different Health-care Settings Meet Criteria for a Screening Programme? Systematic reviews of nine UK National Screening Committee criteria. Health Technology Assessment 2009, 13:6.

20. Hegarty K, Bush R: Prevalence of partner abuse in women attending Australian General Practice: A cross-sectional survey. Aust N Z J Public Health 2002, 26:437-442.

21. Sohal H, Eldridge $\mathrm{S}$, Feder $\mathrm{G}$ : The sensitivity and specificity of four questions (HARK) to identify intimate partner violence: a diagnostic accuracy study in general practice. BMC Fam Pract 2007, 8:49.

22. Sullivan LE, Fiellin DA, O'Connor PG: The prevalence and impact of alcohol problems in major depression: a systematic review. Am J Med 2005, 118:330-341.

23. Arch JJ, Craske MG, Stein MB, Sherbourne CD, Roy-Byrne PP: Correlates of alcohol use among anxious and depressed primary care patients. Gen Hosp Psychiat 2006, 28:37-42.

24. Roeloffs CA, Fink A, Unützer J, Tang L, Wells KB: Problematic Substance Use, Depressive Symptoms, and Gender in Primary Care. Psychiatr Serv 2001, 52:1251-1253.

25. Teesson M, Hall W, Lynskey M, Degenhardt L: Alcohol and drug-use disorders in Australia: Implications of the National Survey of Menta Health and Wellbeing. Aust N Z J Psychiatry 2000, 34:206-213.

26. Astbury J, Atkinson J, Duke JE, Easteal PL, Kurrle SE, Tait PR, et al: The impact of domestic violence on individuals. Med J Aust 2000, 173:427-431.

27. Brienza RS, Stein MD: Alcohol use disorders in primary care: do genderspecific differences exist? J Gen Intern Med 2002, 17:387-397.
28. Ulrich YC, Cain KC, Sugg NK, Rivara FP, Rubanowice DM, Thompson RS: Medical care utilization patterns in women with diagnosed domestic violence. Am J Prev Med 2003, 24:9-15.

29. Proudfoot $\mathrm{H}$, Teesson $\mathrm{M}$ : The association of alcohol dependence with general practice attendance. Drug Alcohol Rev 2009, 28:154-159.

30. Access Economics: The cost of domestic violence to the Australian economy: Part 1. Canberra 2005.

31. Gerber MR, Ganz ML, Lichter E, Williams CM, McCloskey LA: Adverse health behaviors and the detection of partner violence by clinicians. Arch Intern Med 2005, 165:1016-1021.

32. Kilpatrick DG, Acierno R, Resnick HS, Saunders BE, Best CL: A 2-year longitudinal analysis of the relationships between violent assault and substance use in women. J Consult Clin Psychol 1997, 65:834-847.

33. Krug EG, Mercy JA, Dahlberg LL, Zwi AB: The world report on violence and health. Lancet 2002, 360:1083-1088

34. Rehn N, Room R, Edwards G: Alcohol in the European Region Consumption, Harm, and Policies. Copenhagen: World Health Organization Regional Office for Europe 2001.

35. Gunn JM, Gilchrist GP, Chondros P, Ramp M, Hegarty KL, Blashki GA, et al: Who is identified when screening for depression is undertaken in general practice? Baseline findings from the Diagnosis, Management and Outcomes of Depression in Primary Care (diamond) longitudinal study. Med J Austr 2008, 188:S119-S25.

36. Wathen CN, Tanaka M, Catallo C, Lebner AC, Friedman MK, Hanson MD, et al: Are clinicians being prepared to care for abused women? A survey of health professional education in Ontario, Canada. BMC Med Educ 2009, 9:34.

37. Feder G, Ramsay J, Dunne D, Rose M, Arsene C, Norman R, et al: How far does screening women for domestic (partner) violence in different health-care settings meet the UK National Screening Committee criteria for a screening programme in terms of condition, screening method and intervention? Systematic reviews of nine UK National Screening Committee criteria. Health Technology Assessment 2009, 13:16.

38. Potiriadis M, Chondros P, Gilchrist G, Hegarty K, Blashki G, Gunn J: How do Australian patients rate their general practitioner? A descriptive study using the General Practice Assessment Questionnaire. Med J Austr 2008, 189:215-219.

39. Radloff $L S$ : The CES-D Scale: a self-report depression scale for research in the general population. Appl Psychol Meas 1977, 1:385-401.

40. Hodgson R, Alwyn T, Brown J, Thom B, Smith A: The FAST Alcohol Screening Test. Alc Alcoholism 2002, 37:61-66.

41. Hodgson RJ, John B, Abbasi T, Hodgson RC, Waller S, Thom B, et al: Fast screening for alcohol misuse. Addict Behav 2003, 28:1453-1463.

42. Babor TF, de la Fuente JR, Saunders J, Grant M: AUDIT. The Alcohol Use Disorders Identification Test. Guidelines for use in primary health care. Geneva 1992.

43. Hegarty K, Sheehan M, Sconfeld C: A Multidimensional Definition of Partner Abuse: Development and Preliminary Validation of the Composite Abuse Scale. J Fam Viol 1999, 14:399-415.

44. Hegarty K, Bush R, Sheahan M: The Composite Abuse Scale: Further development and assessment of reliability in two clinical settings. Viol Vict 2005, 20:529-547.

45. Ware J, Kosinski M, Keller SD: A 12-Item Short-Form Health Survey: construction of scales and preliminary tests of reliability and validity. Med Care 1996, 34:220-233.

46. StataCorp: Stata Statistical Software. Texas: College Station, StataCorp LP, Release 102007.

47. Britt $\mathrm{HC}$, Harrison CM, Miller GC, Knox SA: Prevalence and patterns of multimorbidity in Australia. Med J Aust 2008, 189:72-77.

48. Ramsay J, Richardson J, Carter YH, Davidson LL, Feder G: Should health professionals screen women for domestic violence? Systematic review. BMJ 2002, 325:314.

49. Duxbury F: Recognising domestic violence in clinical practice using the diagnoses of posttraumatic stress disorder, depression and low selfesteem. Br J Gen Pract 2006, 56:294-300.

50. Feder G: Responding to intimate partner violence: what role for general practice? Br J Gen Pract 2006, 56:243-244

51. Kaner EFS, Beyer F, Dickinson HO, Pienaar E, Campbell F, Schlesinger C, et al: Effectiveness of brief alcohol interventions in primary care populations. Cochrane Database Syst Rev 2007, 18(2):CD004148. 
52. Hegarty $K$, O'Doherty L, Gunn J, Pierce D, Taft A: A brief counseling intervention by health professionals utilising the 'readiness to change' concept for women experiencing intimate partner abuse: The weave project. J Fam Stud 2008, 14:376-388.

53. MacMillan $\mathrm{HL}$, Wathen $\mathrm{CN}$, Jamieson $\mathrm{E}$, et al: Screening for intimate partner violence in health care settings: a randomized trial. JAMA 2009, 302:493-501.

54. Hegarty K, Taft A, Feder G: Working with the whole family when domestic violence is present: what do generalists need to know? BMJ 2008, 337:346-351.

\section{Pre-publication history}

The pre-publication history for this paper can be accessed here: http://www.biomedcentral.com/1471-2296/11/72/prepub

doi:10.1186/1471-2296-11-72

Cite this article as: Gilchrist et al.: The association between intimate partner violence, alcohol and depression in family practice. BMC Family Practice 2010 11:72

\section{Submit your next manuscript to BioMed Central} and take full advantage of:

- Convenient online submission

- Thorough peer review

- No space constraints or color figure charges

- Immediate publication on acceptance

- Inclusion in PubMed, CAS, Scopus and Google Scholar

- Research which is freely available for redistribution

Submit your manuscript at www.biomedcentral.com/submit 